\title{
A Method for Estimation of Free Mica Particles in Aggregate Fine Fraction by Image Analysis of Grain Mounts
}

\author{
Eva Johansson, Karel Miskovsky, Karl-Johan Loorents, and Ola Löfgren
}

(Submitted February 23, 2007; in revised form May 2, 2007)

\begin{abstract}
The need to evaluate free mica grains in fine fraction of aggregate products has initiated the development of a statistically and scientifically acceptable method. The proposed method is based on a modified pointcounting approach using digital micro photos of thin sections of aggregate grains and a software package to sustain sample analysis. A thin section of aggregate grains provides permanent sample documentation readily available for complimentary or other analysis. Statistical analysis, together with a repeatable analysis of samples (permanent mounts), confirms the robustness of the method. The method is appropriate as a complementary assessment tool to estimate and trace changes or variations in quality of rock aggregate. Though, the estimation of free mica particles in fine fraction needs to be combined with other analyses, e.g., petrographic analysis and analyses of mechanical properties, to assess the quality of any rock material. As the samples can be collected from drill cuttings, i.e., an accessible residual product obtainable from surveying or production, the present method is particularly useful as a surveying tool and in prospecting and projecting activities.
\end{abstract}

Keywords aggregates, fine fraction, free mica particles, image analysis, point-count method

\section{Introduction}

The fine fraction of crushed rock aggregates produced from mica carrying rocks can cause considerable damages on road constructions, especially within regions dominated by temperate climate. The reason for these economically perceptible problems is the ability of mica to take up and hold water or bitumen. This ability is partly due to the increased specific surface area of mica rich aggregates, i.e., stemmed from the grain shape of micas. The specific surface of a particle is the ratio of its surface area to its mass, where the main controlling factors are particle size and particle geometry. Furthermore roughness of the external surface, shape, porosity, and mineralogy may contribute to an increase in the surface area (Ref 1). High water content in unbound application layers may be the basis for a raised pore water pressure under load, consequently causing a lowering of the constructions' bearing capacity. For an optimum performance, the aggregates surfaces in a mix are intended to be covered by a bitumen film. Substituting the fine material (i.e., filler) in an asphalt mixture with a material of

Eva Johansson and Karel Miskovsky, Department of Civil, Mining and Environmental Engineering, Luleå University of Technology, 971 87 Luleå, Sweden; Karl-Johan Loorents, Swedish National Road and Transport Research Institute (VTI), 58195 Linköping, Sweden; and Ola Löfgren, Ekovision nord, Granvägen 22, 92232 Vindeln, Sweden. Contact e-mail: eva.johansson@ltu.se.

dissimilar specific surface area will influence the thickness of the bitumen film and thus the asphalt mixture properties, given that the binder content is constant. The sorbing ability of mica may accordingly cause an early constructional deterioration (Ref 2-4).

Aggregates for construction purposes extracted from hard rock quarries are tested and sampled according to national standardization programs, e.g., European Committee for Standardization $(\mathrm{CEN})$, by means to certify the aggregate product, i.e., to ensure that the aggregate product meets the quality demands for the intended use (e.g., CEN). Still, free mica particle content or acceptable threshold limit values of free mica particles contained in the aggregate product are not precisely dealt with in this realm of standards. Furthermore it is not uncommon, in road construction projects, that a large quantity of materials used for the construction is extracted within the construction site. For this sort of materials the aggregate quality assessment may be far less rigorous than compared to materials extracted and produced from a quality certified hard rock quarry. Thus, where applicable, there is a risk that the construction project may not reach a rational usage of natural resources and not limit the impact caused by erroneous usage of materials. A road construction project is one where mass and material balance has been achieved. To accomplish this, information about the materials quality and potential use must be obtained early on in the project planning, which calls for evaluations methods fit for field investigations.

In an effort to verify the content of free mica particles in crushed rock aggregates and to limit damages on road constructions related to the mica content, the Swedish Road Administration (SRA) established a standard method in 2002 concerning the content of free mica in fine fraction of aggregate products (Ref 5). The method is based on a particle count (stereoscopic microscope) and provides an approximation of 


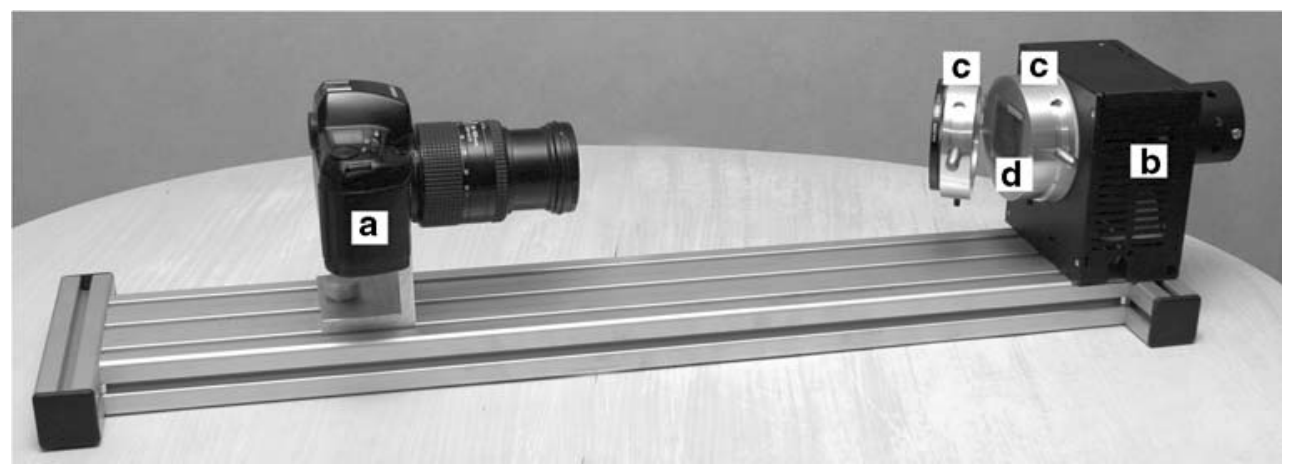

Fig. 1 The photographic set up; (a) digital camera, (b) illuminator equipment with a halogen light, (c) nicoles and (d) a thin-section/sample holder

the content of free mica for grain size fractions between 0.125 $0.25,0.25-0.5$, and $0.5-1 \mathrm{~mm}$. It is mainly suited as an indicative tool as sample selection and counting may introduce a statistical bias and reproducibility is questionable within the same sample. Thus the introduction of the standard method demands the development of an effective and from a scientific point of view satisfactory method for estimation of free mica particles in fine fraction.

The present paper presents a method based on a modified point-count approach using micro photos of grain mounts and an analysis software package. An ample range of field samples can be used as long as the prerequisite amount and grain sizes are met for analysis. Statistical analysis together with a repeatable analysis of samples provides a robust method for mineralogical analysis of the fine fraction.

\section{Description of the Method}

\subsection{Samples}

The demonstrated method is applicable to any sample of fine-grained rock material originating from, e.g., rock aggregate products or drill cuttings from surveying and production. The fine-grained fraction samples $(0.125-0.25,0.25-0.5$ and 0.5 $1 \mathrm{~mm}$ ) used for testing and evaluation of the method are collected from three different quarries consisting of; mica rich meta-tonalite (five samples), veined meta-greywacke (three samples), and mica poor granite (three samples).

\subsection{Preparation}

The sample (ca $500 \mathrm{~g}$ ) is washed on the sieve $0.63 \mathrm{~mm}$ and dried. Following drying the sample is dry sieved and 5-10 $\mathrm{g}$ of each of the following size fractions are collected; 0.125-0.25, $0.25-0.5$, and $0.5-1 \mathrm{~mm}$. The procedure is preferentially performed according to standard methods such as EN 9322:1999 (Ref 6) and EN 933-1:1997 (Ref 7).

From each of the collected size fractions grain mounts is prepared. The collected grain amount (5-10 g) for each size fraction ensures a high-enough grain frequency on the glass microscope slide (Ref 8,9) and satisfies constrains of the statistical calculation.

Images may be acquired by using any equipment that have the utility of using polarized light. In the present work, a digital single-lens reflex camera (digital SLR) fitted with a macro lens was used for recording images. The photographic setup allows single- and cross-polarized light (Fig. 1) to be used. An image size of $3072 \times 2048$ pixels was further reduced to $1810 \times 1810$ pixels to meet the requirements of the image analysis software package.

\subsection{Image Analysis}

The image analysis is performed by means of a software package that is a Microsoft Office Excel add-in (compiled Excel Macro). The mineralogical composition of the sample is estimated by manually marking grains according to its sorting (i.e., two categories, mica and others) in the image. Identification of the common sheet silicate minerals biotite, muscovite, and chlorite is feasible as they are readily distinguished from rock-forming minerals such as quartz and feldspar in polarized micro images. Quartz and feldspar exhibit a low-relief and grey color, while mica minerals have a higher-relief and show other colors than grey. Biotite is often brown or greenish and muscovite varies between red, blue and green color. The chlorite shows anomaly colors, i.e., it changes from black to grey-blue. If hornblende is present, it may be mistaken for biotite. In such cases it is recommended to use pleochroitic colors in single-polarized (plane light) micro photos. In planepolarized light biotite is brown in color and hornblende green. Optical identification of minerals is extensively discussed in the literature, e.g., (Ref 10).

An example of a processed image is shown in Fig. 2, in which counting lines (scan lines) and grains marked according to its mineralogical category by grey or white dots, is displayed. As the manual mineral identification is completed, the information is processed and statistics is computed. The outcome is presented in tables showing the sum of counted grains (both mica and others) and the average of mica. Other statistical information such as standard deviation, variance, minimum and maximum value, and confidence interval are also presented.

\section{Discussion and Evaluation}

Analyses of fine fractions from drill cuttings have a long history as a surveying tool extensively used within ore prospecting. But within the field of prospecting for aggregates or quarry aggregate quality programs, traditionally surveying 


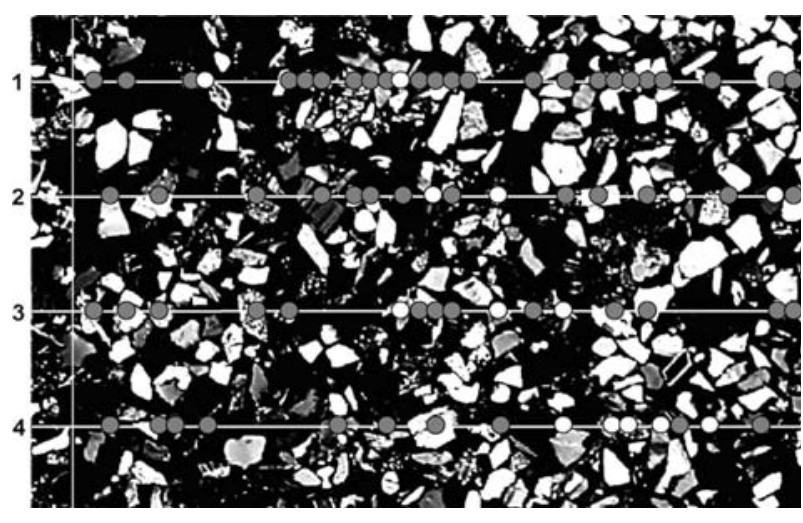

Fig. 2 A section of a processed image. White dots represent mica minerals and grey dots other minerals

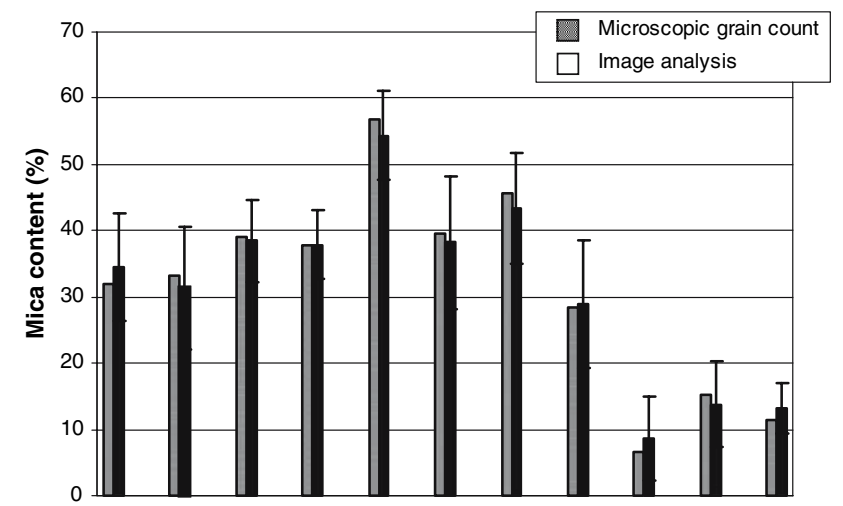

Fig. 3 Comparison of mica content obtained by image analysis and by microscopic grain count analysis of grain mounts. A confidence interval $(99 \%)$ is established for estimates given by the image analysis method

uses the more expensive drill-cores for petrological and mechanical analyses. Thus in this context the present work presents a "new" analysis method as fine fractions from drill cuttings have not, or to a very limited extent, been used in aggregate quality assessment as described in the literature. The main potential of the proposed analysis method is its time and cost effectiveness, notably capable within; mass- and material balance matters (e.g., road and railway cuttings), establishment of quarries and quarry production control programs. Rock material is a non-renewable natural resource which necessitates rational usage, thus aggregates must meet the constructoral requirements otherwise it may cause substantial damages. As the samples can be collected from drill cuttings, i.e., an accessible residual product occurring in several constructing and quarrying stages, the present method is useful as a surveying tool for prospecting and projecting.

One advantage of the photographic hardware used in the current study is the ability to capture the entire thin section in one photographic shot. The photographic equipment is easy to handle as is any changes of pictures (e.g., produce black and white and single-polarized images) or handling due to the use of a digital SLR.

Using samples in the form of a permanent grain mount provides a great documentation of any aggregate-orientated activities. This is especially valuable considering that at any

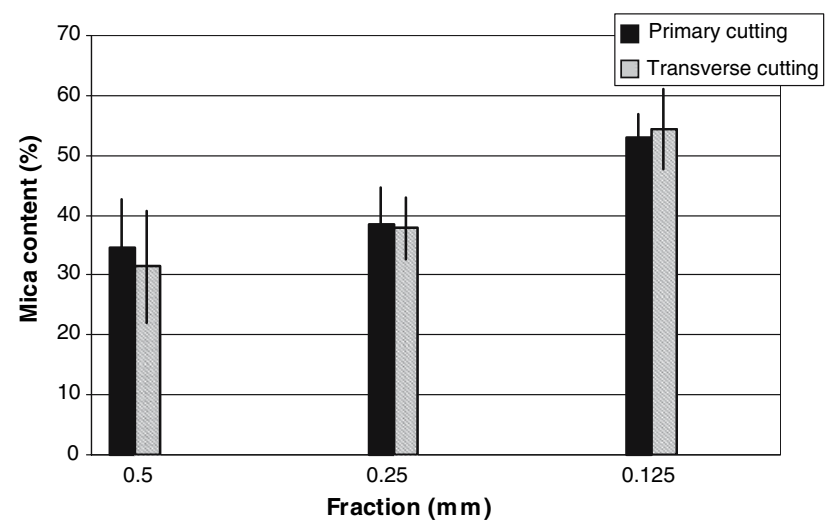

Fig. 4 Comparisons of mica content obtained by image analysis of cross-cut thin sections. Analyses were performed on three different fractions. Mean $\pm 99 \%$ confidence interval is given

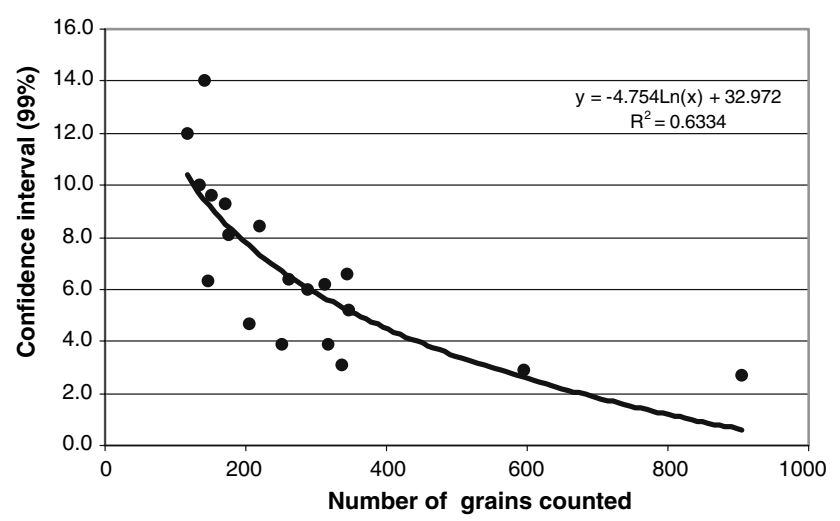

Fig. 5 The relationship between confidence interval (99\%) of the estimation mean free mica particle content in a sample by image analysis and the number of grains counted

occasion the thin section can be re-analysed or further examined.

Estimates of free mica particle content in aggregate fine fraction obtained by image analysis were compared with results obtained by grain count analysis in polarizing microscope along the cross line of minimum length of $4 \mathrm{~cm}$. Eleven samples from three different localities and with different mica content were compared. In each sample, 400-600 grains were counted. No obvious differences between the results obtained by the two methods could be observed. On the contrary, accordance of particle mica content was very good in all samples (Fig. 3).

In order to examine the possible preferred orientation of mica in the epoxy mould three cross sections of the same sample was produced and analysed. Comparisons of mica content obtained by analyses of cross-cut sections are given in Fig. 4. The results revealed no distinct differences between the two methods of cutting.

It is well-known that the number of grains counted is crucial to the reliability of the estimates of free mica content in a sample. These problems are dealt with in power analysis, which is described in many statistics textbooks, e.g., (Ref 11). For this reason, the reliability of 19 samples given by the confidence interval for the estimates of mean mica content was analysed. The results were plotted against the number of grains counted in each sample (Fig. 5). There was a distinct decline in the 
confidence interval with increasing number of grains counted, i.e., the reliability of estimates increased. The relationship was not linear and correlation analysis performed with Sperman's Rho revealed $r=0.77, n=19$, and $p<0.005$. The best-fit for the relationship was given by logarithmic regression $\left(R^{2}=0.66\right)$. The equation for the relationship is given in Fig. 5. Furthermore, the results suggest that at least 350 grains should be counted to obtain a certainty of $3-4 \%$ in the estimate of the average free mica particle content.

The statistical evaluation points out the certainty and repeatability of the method. Due to the possibility to save the images of the statistical operation, the results of the method are controllable. These factors mentioned make the method satisfactory from a scientific point of view.

\section{Conclusion}

The need to quantify the content of free mica particles in fine fraction of aggregates has initiated the development of an analysis method that focuses on the estimation of hard rock quality based on image analysis. A further aspect is that, from a scientific point of view, the described method is statistically satisfying, thus the present work is a step in the right direction of development.

The sample can originate from any rock material, i.e., not only from drill cuttings. Hence, the method is appropriate as a complementary assessment tool to estimate and trace changes or variations in quality of rock aggregate products. Though, the estimation of free mica particles in fine fraction needs to be combined with other analyses, e.g., petrographic analysis and analyses of mechanical properties, to assess the quality of rock material.

\section{Acknowledgments}

This work is funded by the Swedish Road Administration (SRA) and the Swedish National Road and Transport Research Institute (VTI).

\section{References}

1. S.L. Brantley and N.P. Mellott, Surface Area and Porosity of Primary Silicate Minerals, Am. Mineral., 2000, 85, p 1767-1783

2. K. Miskovsky, Enrichment of Fine Mica Originating From Rock Aggregate Production and Its Influence on the Mechanical Properties of Bituminous Mixtures, J. Mater. Eng. Perform. 2000, 13(5), p 607-611, ASM International

3. H. Hakim and S. Said, Glimmer $i$ bitumenbundna beläggningar-Inverkan av fina, fria glimmerkorn, VTI notat 8-2003, Statens väg-och transportforskningsinstitut (the Swedish National Road and Transport Research Institute), Linköping, 2003, in Swedish

4. P. Nieminen and R. Uusinoka, Influence of Quality of Fine Fractions on Engineering Geological Properties of Crushed Aggregates, Bull. Int. Assoc. Eng. Geol., 1986, 33, p 97-101

5. "Bestämning av glimmerhalt i materialets finfraktion", VVMB 613, VV Publ nr 2001:100, Swedish Road Administration, Borlänge, 2002, $6 \mathrm{p}$, in Swedish http://www.vv.se/filer/publikationer/mb613.pdf

6. "Tests for General Properties of Aggregates-Part 2: Methods for reducing laboratory samples", EN 932-2:1999, European Committee for Standardization, 1999

7. "Tests for Geometrical Properties of Aggregates - Part 1: Determination of Particle Size Distribution-Sieving Method", EN 933-1:1997, European Committee for Standardization, 1997

8. I. Sims and P. Nixon, RILEM Recommended Test Method AAR-1: Detection of Potential Alkali-Reactivity of Aggregates-Petrographic Method, Mater. Struct./Matér. Construct., 2003, 36, p 480-496

9. W.D. Nesse, Introduction to Optical Mineralogy, Oxford University Press, 2004, p 348

10. W.A. Deer, R.A. Howie, and J. Zussman, An Introduction to the RockForming Minerals, 2nd ed., Pearson Education Limited, 1992, p 696

11. R.J. Larsen, L. Morris, and I. Marx, An Introduction to Mathematical Statistics and Its Application, Prentice-Hall Inc., 1981, p 536 